\title{
Mapping green technologies literature published between 1995 and 2019: a scientometric review from the perspective of the manufacturing industry
}

\author{
Muhammad Shahjahan Usmani ${ }^{1} \cdot$ Jianling Wang ${ }^{1} \cdot$ Naveed Ahmad $^{2,3}$ (D) Muzaffar Iqbal $^{4} \cdot$ Rahil Irfan Ahmed $^{5}$
}

Received: 6 October 2020 / Accepted: 11 March 2021 / Published online: 11 April 2021

(C) The Author(s), under exclusive licence to Springer-Verlag GmbH Germany, part of Springer Nature 2021

\begin{abstract}
This study presents a comprehensive literature review and gives an insight into the increasing research trends that are based on the discipline of green technology (GTs) in the manufacturing industry. Prior research in this field indicates that there is a scarcity of research on the topic. Therefore, this study seeks to draft a multi-perspective literature review that is based on GTs in the manufacturing industry. Moreover, to make this analysis more detailed, the science-mapping technique and the quantitative approach were also applied on 5734 bibliographic references that were extracted from the web of science. Ultimately, the focus of the research is to understand the tendencies and trends in journals, institutions, and the main areas of research, along with the integration style of these elements in the previous literature that has been written on the subject of GTs. This technique also helps to fill in the research gap, address the limitations of existing literature, and shed light on the various possible directions this could lead to for future research. The implications of this research offer wide directives for editors, researchers, research institutions, policymakers, and practitioners.
\end{abstract}

Keywords Green technologies $\cdot$ Manufacturing industry $\cdot$ Global research $\cdot$ Scientometric review

\section{Introduction}

Over the years, heavy industrial activities have resulted in the damage to people's health, cancer, rising health costs, smog, metal pollution in the water, deforestation, higher levels of pollution, depletion of natural resources, and a loss of ocean biodiversity (Ali Razi et al. 2019; Arshad et al. 2020; Fernández-Navarro et al. 2017; Pacala and Socolow 2004; Ravindra and Mor 2019; Zeng and He 2019). Moreover,

Responsible Editor: Philippe Garrigues

Jianling Wang

wangjl@xjtu.edu.cn

Naveed Ahmad

naveedahmad@mail.nwpu.edu.cn

Muhammad Shahjahan Usmani

Shahjahan@stu.xjtu.edu.cn

Muzaffar Iqbal

m.shah@tju.edu.cn

Rahil Irfan Ahmed

rahil@stu.sxufe.edu.cn health and environmental conditions have severally been affected by industrial pollution, and cancer is now a rapidly spreading disease, due to the rising air pollution discharge that is primarily led by industrial action in the towns of Spain (Fernández-Navarro et al. 2017). Moreover, smog (a mixture of industrial smoke and fog) is also becoming a common phenomenon in the winter season, due to the increasing industrial pollution (Ali et al. 2019). In this regard, the adverse effects of industrial pollution are equally contaminating

1 School of management, Xi'an Jiaotong University, Xi'an, Shaanxi, People's Republic of China

2 School of management, Northwestern Polytechnical University, Xi'an, Shaanxi, People's Republic of China

3 Department of Business Administration, Lahore Leads University, Lahore, Punjab, Pakistan

4 College of management and economics, Tianjin University, Tianjin, People's Republic of China

5 School of Business Administration, Shanxi University of Finance and Economics, Taiyuan, China 
groundwater, as found in a research conducted in the vicinity of Chandigarh, a city in the Indian side of Punjab (Ravindra and Mor 2019). In addition to this, industrial pollution is also increasing the health costs (Zeng and He 2019) of the residents, due to the increase in the incidence of various diseases that are caused by industrial pollution. Moreover, the scope of this industrial pollution's impact is quoted to be vast in nature and is one of the leading causes of deforestation (Murshed et al. 2020), natural resource depletion (Hussain et al. 2020), elimination of ecology (Sejati et al. 2020), rising global temperatures (Mahmood et al. 2020), melting glaciers (Kumar et al. 2020), rising sea levels, floods (Yoo and Suh 2020), frequent natural disasters (Chandio et al. 2020), crops destruction and rising food insecurities (Gupta et al. 2020), and rising health issues due to Covid-19 as well (Coccia 2020). This is mainly because of the weak immunity levels of people, as a result of exposure to industrial pollution over a long period of time (Barbasz et al. 2020).

The leading cause of industrial pollution is the use of traditional technologies, for the production processes (Martins et al. 2018), which not only negatively affect the environment but also put forth social and economic costs to society. Moreover, there is also an enormous pressure on researchers for conducting promising research on GT, in order to mitigate the adverse effects of traditional technology on the environment (Wang et al. 2019). In this review article, the authors mainly focus on GTs or environmental technologies, which are believed to possess the potential to reduce the negative impact on the environment. GTs are environmentally friendly technologies that support sustainable production. For this purpose, the terms environmental technology, clean technology, and sustainable technology been used interchangeably in the existing literature. However, this particular study has considered "green technologies" (GTs) as the central theme of the study.

The role of green and sustainable technologies is beneficial for protecting the environment, and recently, it has been discussed intensively in the literature that has been developed in this field of study (Chen et al. 2019). It is noteworthy that environmental pressure is the chief driving force of GTs' adoption around the globe (Kurnia et al. 2015). Moreover, environmental pressure is also an efficient way to promote environmentally friendly technologies and also adhere to sustainable practices in different manufacturing firms (Vergragt et al. 2014); and this goal is achievable through an effective and impactful green campaign. However, there is a considerable challenge for practitioners to adopt GTs for sustainable productions. Besides this, stakeholders are also hesitant due to the possibility of failure in the process of commercialization of the green idea. This is primarily because this technology is still in the stages of infancy and will take a considerable amount of time before it can effectively come into practice. In a study conducted by Xia et al. (2019). Results revealed that sustainable development-based training of firms' employees helps in the adoption of GTs. Furthermore, several effective regulations have also been drafted to deal with emerging environmental issues that exist in firms (Elcock et al. 2000; Rennings et al. 1999). Other than this, certain financial policies have also been developed for reducing the GHG emissions and the energy efficiency issues that occur under the ever changing economic conditions (Bosquet 2000; Netusil and Braden 2001; Scholtens 2005). One such study also discussed how additional investments in GTs enhance the environmental performance of firms (Da Motta 2006; Shi et al. 2017). Therefore, the aim of the researchers is to involve stakeholders in the innovation processes, while considering impending ways to motivate firms for the early adoption of GT, in various departments (Xia et al. 2019).

It is commonly known that research about the adoption of GTs is still in the initial stages, and there are multiple challenges that come in the way of successfully convincing firms to adopt sustainable technologies. The truth of the matter is that there is a lack of awareness among stakeholders about the advantages of GTs over traditional technologies. By and large, traditional technologies tend to make use of fossil fuel, which severely pollutes the environment. Hence, replacing traditional technology with GTs is expected to positively affect the environment by reducing the amount of pollution and reducing the cost of production. Therefore, a consensus about the adoption of GTs needs to be developed, which will ensure economic and social growth, without negative implications on the environment (Vergragt et al. 2014). However, in reality, this is not as easy as it seems, as the adoption of new technology is time-consuming and involves various barriers when it comes to dealing with the adoption and implementation of GTs in business operations (Xia et al. 2019). Xia et al. (2019) reveal that firms and managers often face critical issues in implementing GTs in the manufacturing process. Furthermore, the unnecessary focus of researchers on aligning the firm's goals with the green campaign tends to negatively affect the interest of other stakeholders that might be involved in the process. The incomplete transformation of GTs therefore pose the possibility of demoralizing suppliers, because this would not have any potential commercial value. Therefore, the financial performance of business operations, along with this hurdle, may depress the stimulus for GTs innovation among the relevant stakeholders (S. Wang et al. 2018). Thus, for a better environment, and for the sustainable financial performance of the firms, an insight into the elements and circumstances of the successful implementation of GTs is mandatory. In addition, this will also create harmony between the operations of the firms and the expected technical solutions during the transition of GTs. The adoption of GTs will also open the doors for achieving green competitiveness for firms while helping to foster sustainable development and reduction in the emission of GHGs. 
The increasing interest of academia, industry, and social scientists in sustainable issues is the main motivation of the current study. The concept of GTs has gained a significant attention over the last few decades, but on the contrary, little research is available to compile the consolidated literature pertaining to the incidence of GTs over the course of these couple of decades. Additionally, due to a significant amount of production and industrial activities in the manufacturing sector, there is a greater need of GTs, which has motivated the researchers to discuss green issues and the prevailing trends these days. There are various studies (Bollinger 2015; Bressler et al. 2011; Cohen et al. 2015a; Cohen et al. 2016; Cunha-E-Sa and Reis 2007; Darko et al. 2020; Hottenrott et al. 2016; Isik 2004; Ong 2012; Wang et al. 2020; Xia et al. 2019; Yao et al. 2020; Zailani et al. 2014) which have discussed the different aspects of GTs adoption. Most of these studies, however, focus on the technical and operational characteristics of implementing GTs in different scenarios. Despite their meaningful contributions, these extant studies neither discuss nor visualize the successful and smooth adoption of GTs into the manufacturing industry. Therefore, it is necessary to have a view of more recent trends and future research directions regarding the adoption of GTs in the manufacturing industry. In order to pursue the research of GTs objectively, there is a need to map out and review the clusters of GTs adoption research.

Mapping and visualizing research that pertains to GTs, in the manufacturing sector, could contribute in various ways: (1) firstly, it would prove to be a valuable addition in the GTs literature, as the current literature lacks a comprehensive and scientometric review on GTs; (2) the extant literature also lacks the presentation of mapping and visualizing trends and themes that are connected to GTs, especially those that are using computerized software. Instead, a rather systematic approach was common in the previous review that has been written on the discipline of GTs; and (3) this research would also be helpful for the scientists of engineering, management, and social sciences, in order to understand the latest progress in the research and development of GTs.

Keeping these intricacies in mind, the structure of the article is as follows: after the introduction part, the second section explains the methodology, which explains the methods of visualization, and the results, along with the discussion part, which explains the findings of scientometric review, and the commentary on the core co-citation clusters. After this, the last part explains the proposed direction future research, followed by the conclusions of the study. In addition to this, it will also add to the existing body of knowledge, by outlining the network of leading researchers, subject categories, and institutions while also discussing recent topics and trends and formulating research clusters. Lastly, this study will also make policy recommendations about the incorporation of GTs in manufacturing industrey.

\section{Methodology}

Scientometrics is a phenomenon where scientific methodology is based on quantitative data and primarily deals with the science of communication (Hess 1997). This technique is widely used to analyze the development of the research processes (Konur 2012). In addition to this, it also organizes scientific information, by recognizing the structure of knowledge. Furthermore, the relevant research drivers have been presented through calculated graphical visuals and mathematical formulae. In this regard, A software named "Cite Space" has been used to conduct the scientometric analysis on green technologies, on the basis of the teachings of Xia et al. (2019). Moreover, different techniques of scientometric that have been practiced in this research include (1) the co-author analysis, which comprises of the co-occurrence of authors, institutions, and countries; (2) the co-word analysis, which recognizes the co-occurrence of subject category and keywords; (3) the co-citation analysis, which comprises of the co-cited authors, co-cited documents, and co-cited journals; and lastly, (4) the analysis of the clusters conducted, based on the cocited documents. These techniques have already been used in various studies and have provided significant insights for on various other disciplines as well (Cobo et al. 2011; Olawumi et al. 2017; Zhao 2017). In addition to this, the analysis of the GTs focused areas required scientific and suitable databases as well. In the light of previous research findings and validity, that have been used in this study as a main database (He et al. 2018; Li et al. 2017; Lin et al. 2019; Marsilio et al. 2011; Olawumi and Chan 2018; Pouris and Pouris 2010; Song et al. 2016), the current databases used for the purpose of this paper are known as the "web of science."

The current research utilizes a science-mapping tool to show the trends that are being followed in the implementation of GTs around the globe. Science mapping is "a generic process of domain analysis and visualization," which aims at the detection of intellectual structure for the scientific domain. Thus, this mapping method aids in visualizing important trends and patterns, with the help of bibliographic data and a significant volume of extant literature (Cobo et al. 2011). In addition to this, it helps researchers to make discoveries in the literature, a process for which other methods are not capable (Su and Lee 2010). Furthermore, studies based on science mapping typically use a scientometric analysis technique or a bibliometric analysis technique (Hosseini et al. 2018b). Bibliometric analysis addresses only the literature that has a comparatively narrow approach toward an issue, as compared to the bibliometric analysis, which comprises of bibliometric data and tools which not only analyze literature but also examine the data output, in order to identify potential insights and trends of the domain (Hood and Wilson 2001). Therefore, a broader scientometric analysis technique has been adopted 
in this particular research. The next few sections explain the recommendations and the framework of the research, which have been formed to complete the next steps. These include the selection of the science mapping tool, the analysis after the collection of data, visual presentation, interpretation, and discussion of the research findings.

\section{Selecting tools for science mapping}

There are a variety of tools of science mapping, which can be utilized for visualizing and analyzing dynamic, temporal, and structural trends and patterns that exist in the previous literature of scientific knowledge (Cobo et al. 2011). Every tool has its own capabilities and strengths, based on the proposed type of analysis. Therefore, the selection of the right tool for the right analysis after a literature review is necessary. The software used for scientific mapping of the current research includes the VOS viewer, Cite Space, and Gephi. The "VOS viewer" is used for presentation, visualization, and exploration of the bibliometric networks (NJ Van Eck and Waltman 2018), while Gephi is used for developing graphs, networks and visualization, which makes it easy to get insight into possible retrievable information from a specific network or graph (Bastian et al. 2009). Lastly, the Cite Space is a tool, which has been developed to meet the needs that pertain to the visual analytic tasks of science mapping (C. Chen 2017) and can explore a significant domain of knowledge, e.g., identifying major research areas, and their related links (C. Chen 2015). References for detailed information about the Cite Space, VOSviewer, and Gephi that can be accessed include C. Chen (2015); Wieringa et al. (2019); and Nees Van Eck and Waltman (2009), respectively. Later sections of this study provide details on all these tools, along with the different types of analysis.

\section{Data acquisition}

The bibliographic data extracted from the Web of Science (WoS), instead of the different databases such as the Google Scholar, Research Gate, and Scopus, was due to its ability to scoop out data from a deeper and wider range of information that this platform offers (Zhao et al. 2019). In addition, the indexed publications in WoS tend to provide the most authenticated information, in comparison to the same offered by the other databases (Meho and Rogers 2008). Moreover, the WoS is a platform that has been referred to largely by the authors of existing review papers, according to their specific disciplines and areas of study (Hosseini et al. 2018a; Hosseini et al. 2018b). Pursuing the existing review papers (Ahmed and Varshney 2011; Ahn 2016; Schiederig et al. 2012; Soares and Soares 2012), different key terms such as "green technology and manufacturing," "sustainable technologies and manufacturing," and "clean technologies and manufacturing" were entered in the databases to retrieve the relevant bibliographic data. It is noteworthy that the current research attempts to discuss all the possible terms are related to the domain in this research (Darko and Chan 2016). Thus, for related future researches, researchers can potentially make use of more related terms, such as environmental technology, clean technology, and sustainable technology. For the purpose of the analysis, the data range entered was "general." That is to say that the range was entered like "1995-2019," and the type of document typed was specifically set to "article." The reason for choosing a duration of time spanning from 1995 to 2019 is the extensive research related to GTs in this specific era. The research based on GTs gained momentum in the late $90 \mathrm{~s}$, and it was essential to cover this era of time, in order to obtain information about the major research trends of the research done on the discipline of GTs. Moreover, the reason for mentioning the type of document to "article" was that the articles of journals written for the purpose of science mapping show highly effective, popular, and certified researches (Santos et al. 2017). Furthermore, in fact many existing research reviews about the manufacturing industry have only made use of these journal-based articles. Therefore, it can be deduced that research articles are the preferred form of data, in order to gain insight for the domain's intellectual structure (Santos et al. 2017). Likewise, while it might be beneficial to add all papers or literature categories on the research topic, it can also be "challenging and costly" (Hosseini et al. 2018b). As a result, all kinds of papers were not considered, because the literature in the database journals might just suitably address the purpose of the research.

On February 13, 2020, the documents were searched from the WoS platform, which retrieved a total of 5736 articles, making data set for this study, and used for literature analysis.

\section{Scientometric techniques}

As described by C. Chen (2017), the scientometric techniques include the authors' co-citation analysis, the keywords cooccurrence analysis, and the document co-citation analysis. In the current study, the science mapping has been done in two levels. The first level comprises of creating networks, according to the rules identified by the citation burst analysis, the keywords co-occurrence analysis, the co-authorship analysis, and the outlets direct citation analysis, which will be explained in the coming section. The next level comprises of creating maps for the extraction of meaningful information that is extracted through a nexus of networks. These networks show the conceptual, intellectual, or social evolution in the research field and discovers patterns, trends, seasonality, and any other outliers (Cobo et al. 2011). 


\section{Results and analysis}

\section{Trends of GTs research and wace in scenario of manufacturing industry}

As presented in Fig. 1, the trend of green technology publications in the manufacturing industry is ranging from the period between the years 1995 and 2019. As compared to the last century (1995-2000), more publications on GTs have been published in the current century (2001-2019). Therefore, it can be deduced that there is an increasing trend in the publications written on GTs, which are also consistent with the implementation of GTs (Darko and Chan 2016; Tseng et al. 2019). Moreover, it is also notable that the publications that have been written on the topic of GTs were retrieved on February 13, 2020. So, the publications, which may appear in WoS, till the year 2019, have been considered for a scientometric review. Moreover, the quantity of publications on the topic (5736 documents) possibly might also rise in the upcoming years, and the date of extracting literature from the database is also consistent with the earlier studies that have been written on this discipline (Hosseini et al. 2018b). Additionally, it is acknowledged that the publications from the period spanning from 1995 to 2000 are comparatively lesser, and this period was considered because of the late adoption of GTs in the manufacturing industry. The upcoming review researches could possibly focus on retrieving additional publications related to this period, which can be done by changing the terms of literature, as mentioned earlier.

\section{Formation of an international body of green technologies knowledge}

\section{Major research domains through keywords network analysis and citation burst}

It is a common practice that examining the foremost keywords helps to discover the focal areas of research
(Shrivastava and Mahajan 2016). As mentioned in Ref. Su and Lee (2010), "keywords represent the core research related to an area." In this regard, a comprehensive network of keywords presents a thorough and impressionable image of the knowledge domain, offering insight through the topics addressed, and how these topics are organized and intellectually linked with each other (Shrivastava and Mahajan 2016). The VOS viewer 1.6.8 software was used to create this network of co-occurrence of keywords, by using the bibliographic data extracted by the WoS. In addition, the authors' keywords have been referred to, for creating a readable and reproducible image of the keywords, instead of all the keywords crammed together with a limited scope of relevance to the area of study under consideration. Following the methodology of fractional counting, a total of 21387 keywords were retrieved from the available dataset, while for the "minimum number of occurrence" needed to set the inclusion criteria for including into major clusters of GTs research, it was essential for a keyword to have appeared 50 times in the search. According to this formula, a total of 70 keywords met this criteria. Besides this, if an irrelevant term were to appear, it was removed by the authors (i.e., "article," "China"). Therefore, the result of this network of keywords comprises of 68 nodes and 1914 edges, ultimately denoting the core areas of GTs, as shown in Fig. 2.

The magnitude of the relationship between two keywords is calculated based on the quantity of the articles in which the keywords appeared simultaneously, thus pointing toward their related research areas (Van Eck and Waltman 2018). A stronger link will ultimately show a more dense line in the visualization network. Moreover, to identify the value of the link in the network, the centrality and the mean of the nodes have also been calculated (Prell 2012), which shows the frequency of the connections of one node with the other (Hosseini et al. 2018b). In addition to this, in order to understand the mutual impact of these nodes, based on the frequency of the links among the nodes, the value is measured through an equation recommended by (Prell 2012)
Fig. 1 Wave and trend of GTs literature in manufacturing industry from 1995 to 2019

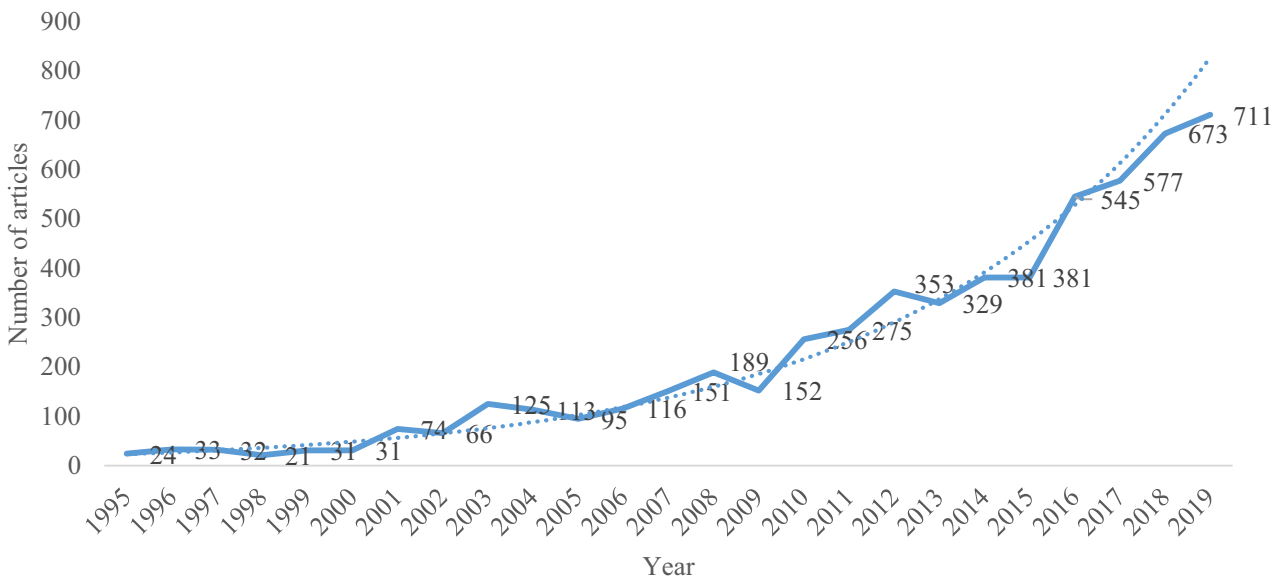


Fig. 2 Major research domains of GTs research in manufacturing industry (keywords cooccurance network)

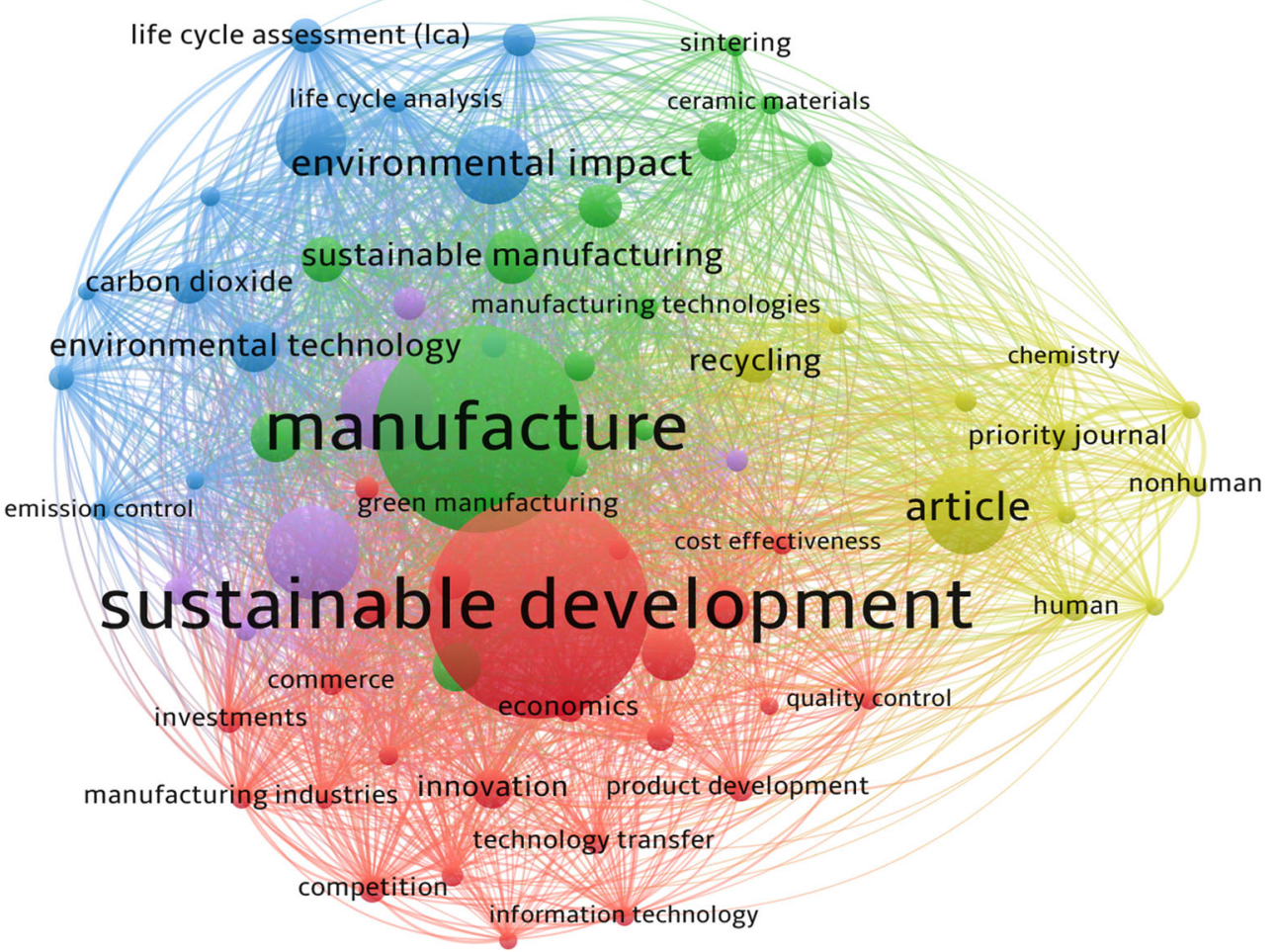

Thus, this equation is given as under:

$D_{i}=\sum_{\mathrm{i}=1}^{\mathrm{n}} X_{i j}$

Here, $D_{i}$ represents the degree of centrality's value for a node $i ; X_{i j}$ shows the accumulation of total links between node $i$ and nodej; and $n$ indicates the total number of nodes in the network. In addition to this, the VOSviewer (Fig. 2) and the Gephi 0.9.2 have been used to calculate the nodes of centrality, as shown in Table 1. It is noteworthy that a higher degree of centrality denotes that the research area is a critical one in nature. However, if the degree of centrality of the tworesearch area is the same, then the respective ranking is calculated, based on the weighted degree value.

This is (weighted degree) a changed version of the degree of centrality, which is calculated while taking the average mean of the value of connections between the given network of nodes.

Other than this, the relationship of the ranking of the links (Table 1), with the research areas (as shown in Fig. 2), shows the main findings and the gap in the literature pertaining to GTs.

- One critical information in this regard is that particular areas of research do not necessarily carry a deeper level of research and, hence, remain isolated. In the previous literature, GTs, sustainable technologies, environmental technologies, the negative consequences of traditional manufacturing technologies, and green investments are studies that have been topics of research studies, in relation to the firm performance. The research on the adoption of GTs is gradually gaining momentum, as a probable solution for a better environment. This is primarily because public knowledge about the quality of environment has risen, and hence, the old culture of "treatment after pollution" is no more in demand. In addition to this, enhancing the sustainability of manufacturing technologies could also help to achieve sustainable development, which a phenomenon that is not being experienced within the existing manufacturing practices.

- It is possible that due to the concept of green washing coming into play, the global adoption of GTs, by the manufacturing industry, has not been able to become a reality. Therefore, adopting sustainable techniques and machines, especially which use GTs for total processes, can attract green stakeholders to a large extant. These studies primarily talk about the earliest adoption of GT (Bollinger 2015; Bukchin and Kerret 2019; Cohen et al. 2015b; Gallagher and Muehlegger 2011; Hottenrott et al. 2016; Pouchepparadjou et al. 2005; Weng et al. 2019; Xia et al. 2019; Zailani et al. 2014) and endorse GTs as an effective solution to achieve sustainable development. However, choosing the nature of the GT, in order to achieve sustainable development, is up to the researchers and the practitioners.

- Besides the environmental quality being the obvious benefit of the adoption of GTs, the literature written on 
Table 1 Main GTs research areas and their relative influence

\begin{tabular}{|c|c|c|c|}
\hline Research focus & Degree centrality & Weighted degree centrality & Relative impact \\
\hline Sustainable development & 77 & 808 & 1 \\
\hline Manufacture & 77 & 725 & 2 \\
\hline Environmental impact & 76 & 281 & 3 \\
\hline Manufacturing & 76 & 335 & 4 \\
\hline Recycling & 76 & 154 & 5 \\
\hline Sustainability & 76 & 339 & 6 \\
\hline Technology & 76 & 184 & 7 \\
\hline Decision-making & 74 & 132 & 8 \\
\hline Environmental technology & 74 & 193 & 9 \\
\hline Life cycle & 73 & 246 & 10 \\
\hline Sustainable manufacturing & 73 & 198 & 11 \\
\hline Carbon & 72 & 95 & 12 \\
\hline Energy efficiency & 72 & 178 & 13 \\
\hline Environmental protection & 72 & 162 & 14 \\
\hline Manufacturing process & 72 & 148 & 15 \\
\hline Costs & 71 & 117 & 16 \\
\hline Economics & 71 & 102 & 17 \\
\hline Environmental management & 71 & 131 & 18 \\
\hline Energy conservation & 70 & 83 & 19 \\
\hline Energy utilization & 70 & 159 & 20 \\
\hline Industry & 70 & 94 & 21 \\
\hline Innovation & 70 & 137 & 22 \\
\hline Investments & 70 & 86 & 23 \\
\hline Carbon dioxide & 69 & 145 & 24 \\
\hline Commerce & 69 & 89 & 25 \\
\hline Life cycle assessment (LCA) & 69 & 125 & 26 \\
\hline Optimization & 69 & 79 & 27 \\
\hline Industrial research & 68 & 170 & 28 \\
\hline Life cycle assessment & 68 & 118 & 29 \\
\hline Pollution control & 68 & 78 & 30 \\
\hline Climate change & 67 & 67 & 31 \\
\hline Supply chains & 67 & 97 & 32 \\
\hline Energy consumption & 66 & 50 & 33 \\
\hline Environmental sustainability & 66 & 91 & 34 \\
\hline Product design & 66 & 106 & 35 \\
\hline Competition & 65 & 93 & 36 \\
\hline Global warming & 65 & 81 & 37 \\
\hline Greenhouse gases & 65 & 86 & 38 \\
\hline Life cycle analysis & 65 & 83 & 39 \\
\hline Manufacturing industries & 65 & 78 & 40 \\
\hline
\end{tabular}

the adoption and advantages of GTs is lacking in terms of the studies that are conducted and published, which could address the following main aspects of GTs research: (1) the actual contribution of GTs to boost firm performance and (2) the way GTs should deliver the desired results, in order to achieve sustainable development.
- When analyzing the previous trends, there have been no studies that exist in the literature, specifically addressing the GTs in the manufacturing industry. In the existing studies, terms like sintering, environmental impact, ceramic material, technology, recycling, industry, design, sustainable manufacturing, unclassified drug, chemistry, carbon dioxide, priority journal, life cycle assessment, procedure, 
metabolism, environmental technology, climate change, decision-making, 3D printer, manufacturing, and green economy have collectively established a major proportion of the literature that is related to GTs, as shown in Fig. 2.

- Besides this, it has been observed that in the extant literature, the social and economic aspects of the GTs adoption are ignored thus far, but the aspects pertaining to the discipline of sustainable environment have become a popular in the context of GTs adoption, which is shown in Fig. 3. Moreover, this is also evident from the analysis of the citation burst, extracted with Cite Space 5.3.R3. In addition to this, when observing the frequently used keywords in the given time period, the literature that focuses on the specific domain is shown by the citation bursts, especially in terms of an emerging subject, or a subject that is linked with the citation surges (C. Chen 2015).This also means that the citation bursts provide access into the geographical areas, which have become popular among researchers. So, the total keywords, which meet the citation threshold are a total of 70 , and a number of almost 23 words from the citation burst are shown in Fig. 3. The top five words, with the maximum strength of the citation bursts, include technology $(10.4633,2007-$ 2013), industry $(9.499,2010-2014)$, sintering (8.808, 1995-2007), environmental technology $(8.5934,2016-$ 2019), and the environmental impact (6.487, 1995-2007). This establishes that in the current years, these are the most important topics to be taken into consideration. The emerging topics in the present years include green innovation, clean, environmental, or green technology, sustainable solutions, and sustainable firm performance.
Analysis of outlet direct citation to represent major research outlets

In all kinds of researches, the analysis of academic journals is considered to be a valuable aspect, in which some of the top journals regarding an area of study are analyzed (Serenko 2010). The analysis of journals provide readers with useful and relevant information, help the authors select a suitable journal to publish their work in, help journal editors to meet goals of their journals, and support libraries and institutions in the optimal allocation of resources that are invested in these journals (Hosseini et al. 2018a). In this review research, the direct citation analysis of the journals has been undertaken in order to highlight the importance of academic journals, which have published studies related to the advent of GTs in the manufacturing industry. For this purpose, the VOSviewer was used, while the unit of analysis was taken to be the "sources," and the kind of analysis was the relevant "citations." Other than this, the "minimum number of articles published by a journal or source" and the "minimum amount of citations of a journal or source" were fixed at a total number of 10. Among the 1439 extracted sources, 33 sources met the criteria of this paper, which appeared in the output network, which comprises of 26 links, between 33 outlets. In addition to this, the visualization of the journals network was done with Gephi. Moreover, for the current research, the weighted degree values were utilized for the size adjustments and the coloring nodes internally (Fig. 4), and the bigger weighted degree values are represented with the thinner and wider node. Also, Table 2 shows the most effective outlets in Fig. 4, which

\section{Top 20 Keywords with the Strongest Citation Bursts}

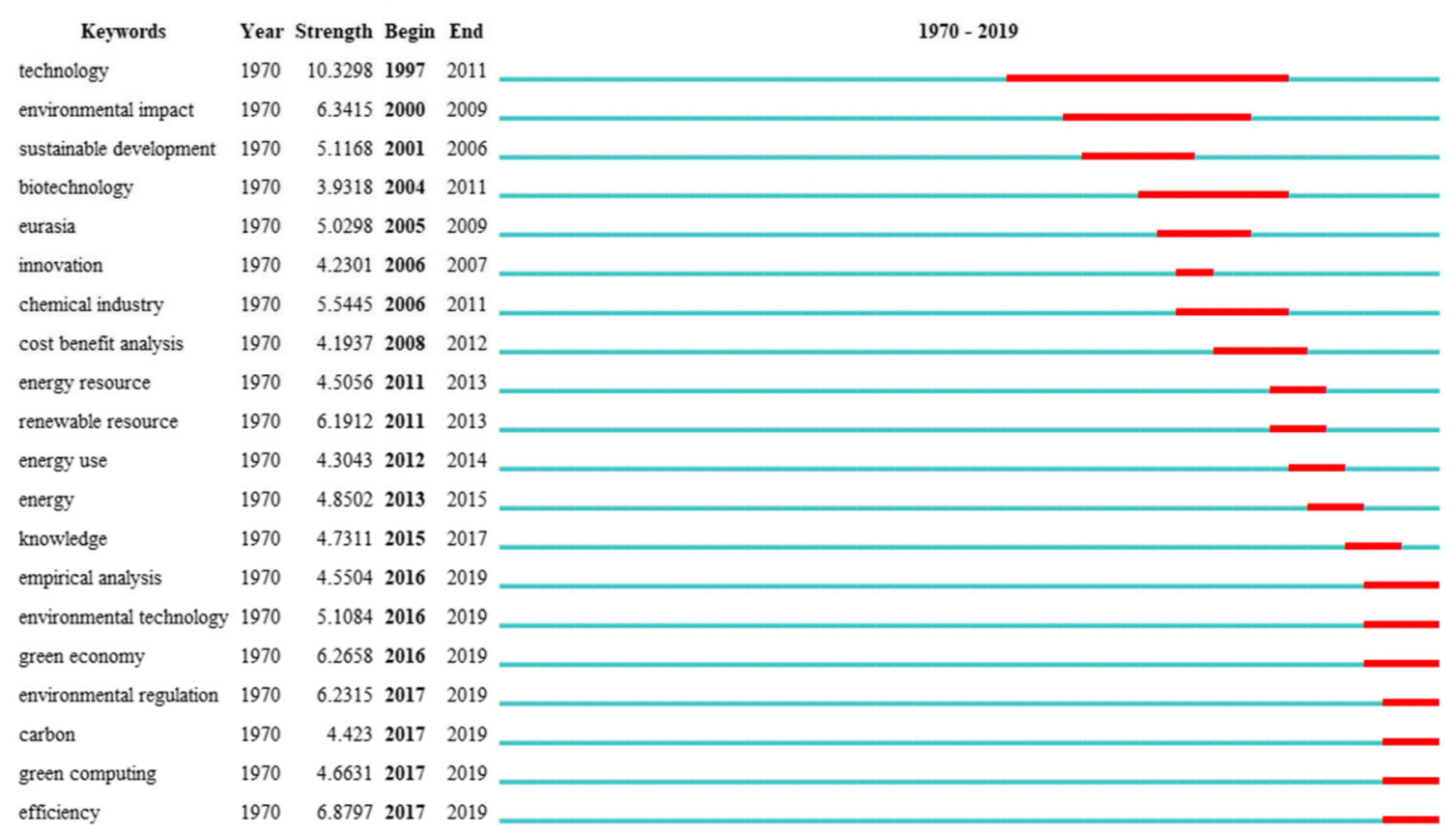

Fig. 3 Represnetation of strongest citation burst for the top 25 keywords 


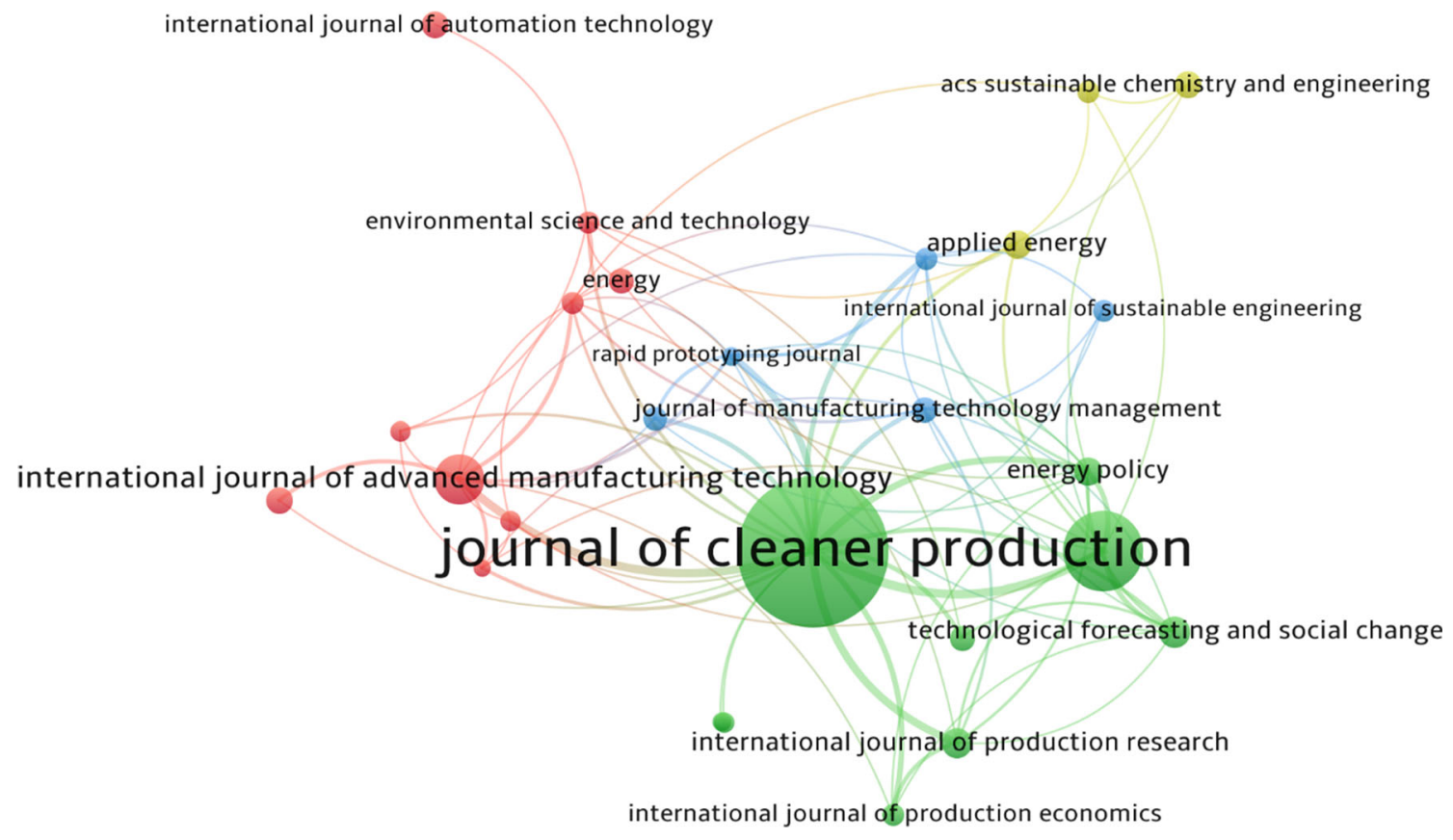

Fig. 4. Main outlets network of GTs literature

are the 15 top ranked journals of green technology adoption that have been placed in order, according to their weighted degree.

Finally, from the findings it is clear that the most significantly relevant and suitable journal for the literature developed on green technology adoption is the Journal of Cleaner Production, with the highest weighted degree value of 116 . It is noteworthy that there are several significant citations that have been extracted from this journal that are specifically directed toward an effective GTs policy. These include journals such as the International Journal of Advanced Manufacturing Technology, Sustainability (Switzerland), and the Journal of Industrial Ecology (as shown in Fig. 4), which are the second layer impact journals in the field (Table 2). Also, the abovementioned five journals might finally be considered as the main reference sources for GTs. Other than this, the Journal of Cleaner Production, which is the most significant journal in the area, may also be supported by the existing research literature. This is because it is mainly aimed toward the environmental aspects pertaining to the adoption of GTs, which prove
Table 2 Main 15 outlets for GTs research

\begin{tabular}{lll}
\hline Sources & Weighted degree value & Rankinga \\
\hline Journal of cleaner production & 116 & 1 \\
Energy policy & 28 & 2 \\
International journal of advanced manufacturing technology & 35 & 3 \\
Sustainability (Switzerland) & 38 & 4 \\
Journal of industrial ecology & 18 & 5 \\
Journal of manufacturing technology management & 16 & 6 \\
Cirp annals - manufacturing technology & 14 & 7 \\
Rapid prototyping journal & 25 & 8 \\
Technological forecasting and social change & 19 & 9 \\
Environmental science and technology & 9 & 10 \\
International journal of production research & 25 & 11 \\
Journal of engineering manufacture & 10 & 12 \\
Applied energy & 8 & 13 \\
International journal of computer integrated manufacturing & 5 & 14 \\
International journal of production economics & 14 & 15 \\
\hline
\end{tabular}

${ }^{a}$ Outlets were ranked based on the weighted degree value 
to be the best fit with the "aim and scope" of the Journal of Cleaner Production. This is primarily because being "fit" is the core factor to be considered, while selecting a journal (Knight and Steinbach 2008).

\section{Collaborative network associated with GTs research: Co-authorship analysis}

To enhance the productivity for a specific research area and to increase the scientific collaboration, availability of incentives and expertise is a necessary measure (Ding 2011; Hosseini et al. 2018b). Extracting such knowledge is the most critical, in order to enhance the academic communication and collaboration, as described by different studies in the past (Glänzel and Schubert 2004). Besides this, "every aspect of scientific collaboration can be reliably tracked by analyzing co-authorship networks." Huang and Chang (2011) added that co-authorship is an important indicator when it comes to the representation of scientific collaboration. If the level of scientific collaboration is low, it shows that there is less interest of the researchers in this area and, therefore, also lower research productivity. The next few sections describe the network of co-authorship, in terms of the GTs literature that has been developed in different contexts.

\section{Institutions}

In institutions, the presence of network collaboration, with a higher degree of interest and intentions for the effective adoption of GTs in the manufacturing industry, provides support in policymaking, partnership, and network creation itself. In addition to this, taking the concept of "organization" as a unit, the VOSviewer has been used for the "co-authorship" analysis, with the help of the "fractional counting" method. In this analysis, the "minimum number of documents of an organization" have been fixed to 20 , and the "minimum number of citations of an organization" have been fixed to 50 . In conclusion, the total discovered number of organizations is 5606 , out of which 143 institutes matched the set criteria, and were therefore, included in the network output. In addition to this, the Gephi software has also been referred to for the visualization. In the Gephi, the hyperlink-induced topic search (HITS), which are generally considered to be the authorities and hubs, is an algorithm presented, whose function is to allocate effective nodes (Khokhar 2015).The HITS algorithm creates two different nodes for each node in the network: a hub score and an authority score. These scores serve different meanings. The bub score usually points out the effectiveness of a node, in a way that it works as a core source of reference. The authority score brings insight into the amount of beneficial information that is saved in the node (Hosseini et al. 2018a). If a node is more influential, then it shows that it has a higher authority score with regard to the source of useful information (Cherven 2015). Detailed information about both the scores can be found in a study that was undertaken by Kleinberg (1999). Before using the HITS method, the hub score in the network for organizations was employed in order to recolor and resize the node of the network of countries and collaborative research. Hence, if the shade is light, and the node is large, it will tend to show higher hub scores.

For instance, institutes from Singapore, China, Australia, Ghana, and Hong Kong have been involved in developing research material regarding GTs in the manufacturing sector, whereas institutes from other countries like Canada, the UK, and the USA show limited cross-linkage institutions (Fig. 5, Table 3). This may show that less attention has been given to the cross-fertilization of GTs ideas among different institutions. Moreover, in order to be more productive in the field of research pertaining to GTs, effective and efficient research collaborations are required across the GTs network as well.

\section{Countries}

The network of scientific collaboration in different countries acknowledge those countries that are active in the research domain related to the chief discipline under consideration (C. Chen 2015). In the VOSviewer, a network has been created in order to distinguish the most collaborative and influential countries. For analysis, the unit has been taken to be the "countries," the type of analysis is taken to be the "co-authorship," and "fractional counting" is considered to be the method for counting. The minimum number of citations of a country has been set to 50 , and the "minimum number of documents of a country" have been fixed up to 20 . Out of the 212 countries under consideration, a

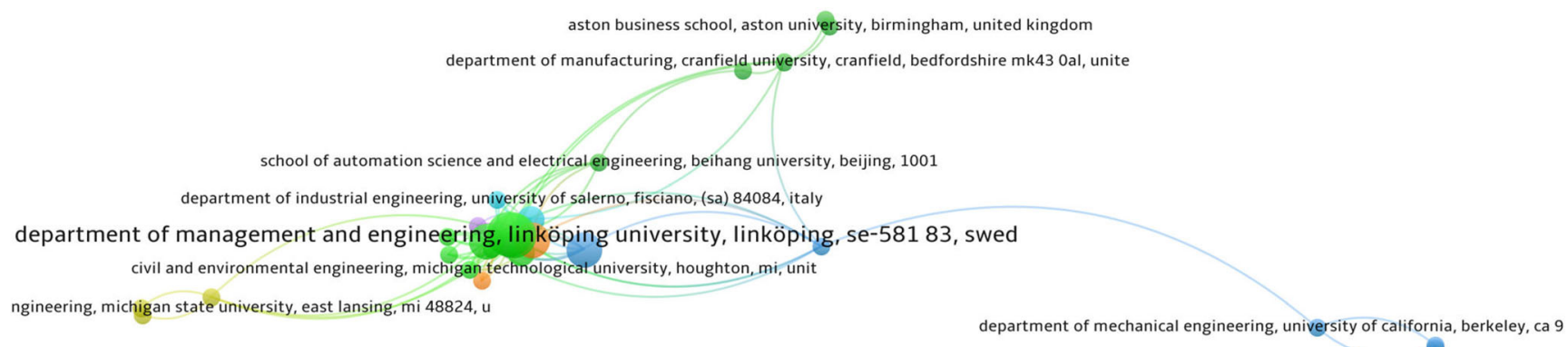

ngineering, michigan state university, east lansing, mi 48824, u

Fig. 5 GTs literature and collaboration network of different international institutions 
Table 3 Collaborative network of different global institutions in global GTs research

Universities with their corresponding departments

\begin{tabular}{ll}
$\begin{array}{l}\text { Weight degree } \\
\text { value }\end{array}$ & Ranking \\
\hline 86 & 1 \\
86 & 2 \\
70 & 3 \\
59 & 4 \\
54 & 5 \\
35 & 6 \\
17 & 7 \\
13 & 8 \\
8 & 9 \\
8 & 10 \\
7 & 11 \\
7 & 12 \\
7 & 13 \\
5 & 14 \\
5 & 15
\end{tabular}

Department of management and engineering, Linkoping university,

Linkoping, Sweden

Key laboratory of contemporary design and integrated manufacturing technology, Ministry of education, Northwestern polytechnical university, Shaanxi 710072, China

Research \& development institute in Shenzhen, Northwestern polytechnical university, China

Department of production, university of Vaasa, pl 700, Vaasa, 65101, Finland

Institute for a secure and sustainable environment, university of Tennessee, Knoxville, United States

Key laboratory of contemporary design and integrated manufacturing technology, Ministry of education, Northwestern polytechnical university, Xi'an, 710072, China

Department of industrial and manufacturing systems engineering, The university of Hong Kong, Hong Kong

Department of production engineering, Kth royal institute of technology, Stockholm, Sweden

Department of manufacturing, Cranfield university, Cranfield, Bedfordshire, United Kingdom

Department of mechanical and aerospace engineering, Syracuse university, Syracuse, Ny, United States

Department of industrial engineering, university of Salerno, Fisciano, (SA) 84084, Italy

Politecnico di milano, department of management, economics and industrial engineering, piazza leonardo da vinci 32, Milan, 20133, Italy

School of automation science and electrical engineering, Beihang university, Beijing, 100191, China

Civil and environmental engineering, Michigan technological university, Houghton, MI, United States

Department of computer science, George mason university, 4400 Fairfax, VA 22030-4444, United States

In order to represent the top effective countries in the im-

total of 33 countries met the study criteria and have been added in the network. These have been then visualized by using Gephi, as shown in Fig. 6.

Fig. 6 GTs literature and countries based collaborative network

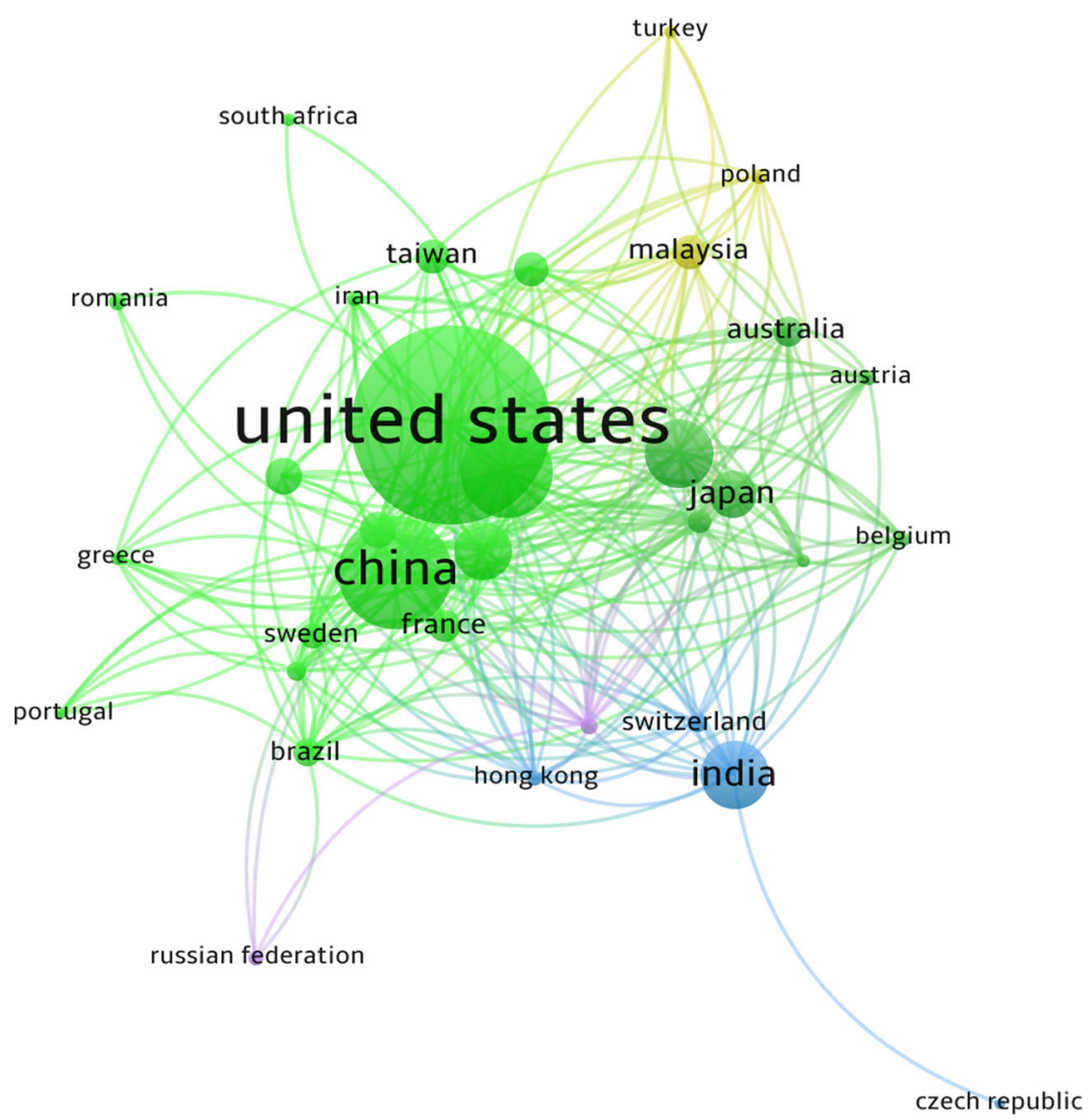


degree values, the nodes have been resized and recolored. The nodes with the lighter shades show low values of the weighted degree, while the bigger nodes show a high value of the weighted degree. In Table 4, the 15 main countries with a higher research incidence of focusing on the discipline of GTs, in the manufacturing industry, were ranked, based on the weighted degree values. The top two countries, the USA and China, are implicitly the highest contributors to the research pertaining to the discipline of GTs. But, the top rank belonging to the USA is not aligned with the findings of Darko and Chan (2016). This is primarily because the USA and China are also large contributors to the world's total carbon dioxide emission (J. Chen et al. 2019). Practitioners and research scholars from these countries believe that incorporating GTs is the only way to attain the ultimate degree of sustainability. The third biggest country in the research related to GTs is the UK. However though, the UK does not enjoy a strong association with China and the USA. The strength of the association among the most influential countries is required in order to design a global policy that is based on nurturing mutual collaborations and sharing knowledge in the study area of GTs adoption. On the other hand, there are highly strong links between China-Australia, China-Hong Kong, China-Japan, USA-Taiwan, and USA-China. However, when running a comparison among 212 countries, just few strong associations have been established. The reason may be that there tends to be a lesser number of comparative cross-country studies in the previous research, which focus specifically on the advent of GTs in the manufacturing industry, with valid theories and findings in various scenarios. Moreover, several countries in the network like Romania, Austria, South Africa, Belgium, Greece, Poland, Portugal,

Table 4 Top 15 nations collaborating in GTs research

\begin{tabular}{lll}
\hline Countries & Weighted degree value & Ranking \\
\hline USA & 444 & 1 \\
China & 360 & 2 \\
UK & 234 & 3 \\
Italy & 216 & 4 \\
Sweden & 176 & 5 \\
India & 165 & 6 \\
Finland & 153 & 7 \\
Germany & 117 & 8 \\
Brazil & 81 & 9 \\
Japan & 80 & 10 \\
the Netherlands & 73 & 11 \\
France & 72 & 12 \\
South Korea & 72 & 13 \\
Hong Kong & 65 & 14 \\
Denmark & 64 & 15 \\
\hline
\end{tabular}

Russian federation, and Czech Republic show weaker links, especially when one considers the major stream of GTs (key nodes), and the members of the network. Therefore, the above-mentioned countries should ideally incorporate the adoption of GTs in their related policies, mainly because they have a weak collaboration in the network of GTs.

None of developing countries have been included in the network. This could primarily be due to different issues that have been faced by the developing countries, such as the lack of awareness and knowledge about green technologies (GTs). Therefore, the gap in availability of the knowledge pertaining to GTs is a hurdle, when it comes to the adoption of GTs in developing countries.

\section{Discussion and recommendations}

Research on green technologies (GTs) started in the 1970s, but in recent times, it has gained attention due to the increasing awareness of environmental issues. In addition to this, the number of research papers published in this area of study has shown an increasing trend in the more recent era, thus verifying the rising concern over sustainable GTs. Therefore, in order to meet this increasing demand, some of the recent global literature pertaining to the discipline of GTs shows a gap in the research, which is clear from the comprehensive analysis of the literature, as shown in Table 1. Moreover, the main focus of the GTs research revolved only around particular themes, while being biased toward the other areas of research that needed as much attention for the greater good of the world. In this context, the focus was primarily on the aspect of environmental sustainability of GTs, while the economic and social aspect of sustainability was neglected. In addition to this, there has also been minimal research on the significant construct that is related to GTs, such as the green or environmental technology anxiety (apprehension of the stakeholders about use and commercialization of the idea, which is still in its stages of infancy) and the adoption of sustainable technologies. Therefore, it is obvious that the previous research only partially covers the literature that is related to the adoption of GTs. The "triple bottom line" in the context of GTs is the sustainable incorporation of economic, environmental, and social aspects that exist in manufacturing firms (Elkington and Rowlands 1999) . In order to gain the optimum benefit from GTs, focusing only on the environmental aspect is not sufficient. There are several critical activities that are required to address the economic and social sustainability aspects of GTs. Moreover, it is also an agreed upon belief that incentives and rewards could potentially expedite the earliest adoption GTs, which can also be helpful for effective green project management. However, the adoption of GTs faces various challenges, and these may include concepts such as new technology adoption anxiety, commercialization of ideas, 
expensive installation, and a small market share (Bollinger 2015; Cohen et al. 2015b; Gollin et al. 2005; Hottenrott et al. 2016).

There are many sustainable enablers that can be considered to overcome issues that are related to the effective adoption of GTs in manufacturing firms

- Firstly, there is a need to integrate sustainability in the total manufacturing framework, and not just confine the research approach toward a sustainable environment. For instance, the life cycle assessment, which includes the TBL features of a product, should be verified, at every phase of the product life cycle.

- Secondly, green project management tends to have minimal literature written to its name, as compared to the concepts related to conventional projects. Therefore, in the researches that are being undertaken, there is a need to investigate issues that are related to green technologiesbased project academia and industry. Moreover, the creation of joint research clusters can also help to achieve a concept of purpose, which particularly focuses on the issues that pertain to green project management (including optimization, success, and productivity of green projects). These are some of the proposed initiatives in the light of the current scholarship and studies that have been observed (Hwang et al. 2015; Watson et al. 2011; Zhou et al. 2015) for the upcoming researches.

- Thirdly, future researches can also focus on other related or unrelated industries, such as construction, beverages, and the wood industry. In addition to this, technical research is also required in order to design green machinery, which are capable of using green energy. Other than this, besides the requirements that have been mentioned above, the use of GTs is also required due to the factors of sustainability and local climatic conditions (Koebel et al. 2015; Zuo and Zhao 2014). In addition to this, further research is required for the formulation of strategies and the framework, which can remove any potential obstacles and help in the vast application of GTs (Darko et al. 2019).

\section{Implications and recommendations of the study}

Climate change has become a reality that stretches beyond theory. And this theory is now confirmed and is obvious from the severe fluctuations in weather conditions and frequent climatic incidents including tsunamis, floods, storms, wildfires, and the melting of glaciers to name a few. Therefore, in order to address the severity of the issue, there is a dire need to design a policy framework to find sustainable solutions to slow down and perhaps even reverse the process of climate change. The policy implications for firms that are willing to or are in the process of transition of the effective and successful adoption of GTs, practitioners, and the country's policy formulators, regarding planning, executing, and implementation of GTs in the manufacturing industry, need to be addressed as well. Some of these have been discussed below:

- The first implication for firms and policy formulators is that the developing countries lack the capability of adopting GTs, as compared to the more developed nations (F. Wang et al. 2017). For successful adoption, transformation, and sustainable development and implementation of the GTs, developing countries are required to strengthen the application of environment-related regulations.

- Secondly, nationwide policy and incentives are required for the manufacturing industry, at the government level, for the adoption of the GTs. This is because the negative effects of climate change are now affecting the GDP growth of the country. Therefore, the fight against climate change requires rapid action, so as to mitigate the negative effect of climate change.

- Lastly, policymakers must address any hurdles in the way of the commercialization of the idea of GTs to become sustainable. Because if the idea is not effectively formulated and worked upon in concrete terms, then the stakeholders would hesitate to participate and invest in the process of GTs adoption.

This research is a step toward an initial attempt to provide understanding of the literature pertaining to GTs, in the manufacturing industry, over the last 25 years. The results of the study indicate that there is a lack of collaboration among the players (institutions and countries), and this proves to be the main hurdle toward the adoption of GTs, on a global level. Therefore, institutions and countries should collaborate to take an active part in the adoption of GTs. As evidence in the literature suggests, the collaboration among these players was not present or was so weak, due to certain aspects that were weaker in nature. Therefore, a collaborative stance among stakeholders may provide significant benefits in this regard (Scherer 2005). The following recommendations can help to find the answer for the above-mentioned issues:

- The organizations and sponsors, working for the adoption of GTs, must fully endorse research collaboration across different nations, institutions, and departments.

- There is a need to change the way green performance is measured among the relevant stakeholders, and this change must pave way for the endorsement of further research collaboration and green projects. 
- The governments should develop comprehensive national policies, which should include the establishment of green infrastructure, awareness campaigns, and the effective provision of low margin loans for the installation of GTs.

- Moreover, there is need to build a certain level of trust among green stakeholders. This is primarily because this green idea has not been fully commercialized yet; therefore, green business can successfully flourish and meet the demand and supply ends of the green market.

The findings of this study have helped to gather a clearer picture of the body of GTs knowledge. In addition to this, a further understating of two gaps, found in the literature, has been gained. In this regard, as suggested in the findings, the total clusters of GTs were 68 in number, which cover certain issues, followed by the recommendation required to address these issues. Moreover, this research also helps to identify the networks of research. Furthermore, the concerned bodies, which are interested in the GTs research, may better understand the subject due to the manner in which they are interlinked. For practitioners and researchers, this review study aimed to enhance the insights and converge a variety of knowledge, which is required to integrate the state of the art level of GTs.

\section{Conclusion}

This research revolves around the scientometric review of the GTs literature, specifically from the perspective of the manufacturing industry that is typically involved in extreme polluting activities. Conventional technology, which most often leads to financial growth, is not viable for a sustainable planet. Besides, economic growth is a mandatory phenomenon for the massively increasing human needs and issues including climate change (deteriorating environment, rising temperature), increasing poverty, food insecurity, and a lack of access to health facilities, as recently witnessed by the world in the form of a pandemic that killed more than one million people recently, and resulting in a death toll that is still on the rise. As mentioned above, there is a critical need to find a way to meet the needs of the planet, but this is only possible by firstly finding the solutions for the disadvantages of conventional technology that is recently being used in the operations of the manufacturing industry, and extensively powered by the burning of fossil fuels. The one, practical solution for the two conflicting goals is the adoption of GTs, specifically in the operations of the manufacturing industry. This is a win-win situation for the fulfillment of human needs, without damaging the environment of the planet. However, for the optimum, smooth, and effective adoption of GTs, there is a lack of awareness among the relevant stakeholders regarding the environmental, social, and economic benefits of GTs adoption. Therefore, the initiation of this endeavor is required at the state level, in order to make efforts to increase the acceptability and early adoption of GTs. Though initially, the high cost of adopting GTs has been high due to the emerging research trends and the diffusion of technology, the measures taken to mitigate pollution are now becoming obstinately economical. The planning, transformation, and implementation level policies should be extensively focused upon; otherwise the benefits of adopting GTs will be compromised. Moreover, this is also a viable measure for sustainable investment, because over time different countries are taking measures to replace conventional technology with GTs, primarily for the achievement of sustainable economic, social, and environmental goals.

\section{Limitations and future research}

As with all studies, there are certain limitations of the research as well. First, the whole analysis is based on the databases that have been retrieved through WoS, which possesses a few intrinsic drawbacks related to the coverage of the publications. Secondly, relying on a few keywords and article journals is not considered to be sufficient to make conclusions that are completely representative of the empirical situation. Due to the mentioned reasons, the conclusions of this scholarship possibly do not mirror the maximum accessible literature on the GTs. The upcoming researches can most definitely exploit the findings of this study while using different settings for the industries and countries that have been taken into consideration. Thirdly, this research incorporates the principles of social network analysis, featuring citation networks. This can prove to be an easy target for critics to raise objections, due to it being a major indicator of connections, quality, and impact. In addition to this, the limitations of the study, while explaining the findings of the research, must be considered. The future research could add multiple data resources, types, and indicators for evaluating the effect, associations, and quality within the literature, in order to address the limitations of this study. For practitioners and researchers, this review study aims to enhance the insights and converge the variety of knowledge, which is required to integrate the state-ofthe-art level of GTs. Because of these clearly identified study gaps that point toward the different possible research directions, there might be an interest of researchers and practitioners to work for the next level of research pertaining to the discipline of GTs across the globe. Therefore, possible future research efforts should revolve around green policy formulation and infrastructure development in green industries (i.e., the technical aspect of GTs whose demand is on the rise). 
Availability of data and materials Supplementary data to this article will be provided on request.

Author contribution Muhammad Shahjahan Usmani: Formal analysis, writing - original draft

Jianling Wang: Supervision, project administration

Naveed Ahmad: Visualization, reviewing, preparing final draft and formatting

Muzaffar Iqbal: Investigation, validation, writing — review and editing Rahin Irfan: Conceptualization, methodology

\section{Declarations}

Ethics approval Not applicable

Consent to participate Not applicable

Consent to publish Not applicable

Competing interests The authors declare no competing interests.

\section{References}

Ahmed J, Varshney SK (2011) Polylactides - chemistry, properties and green packaging technology: a review. Int J Food Prop 14(1):37-58

Ahn D-G (2016) Direct metal additive manufacturing processes and their sustainable applications for green technology: a review. International Journal of Precision Engineering and ManufacturingGreen Technology 3(4):381-395

Ali Y, Razi M, De Felice F, Sabir M, Petrillo A (2019) A VIKOR based approach for assessing the social, environmental and economic effects of "smog" on human health. SciTotal Environ 650:2897-2905

Arshad Z, Robaina M, Shahbaz M, Veloso AB (2020) The effects of deforestation and urbanization on sustainable growth in Asian countries. Environ Sci Pollut Res, pp 1-22

Barbasz A, Kreczmer B, Skórka M, Czyżowska A (2020) Toxicity of pesticides toward human immune cells U-937 and HL-60. J Environ SciHealth CPart B 55(8):719-725

Bastian M, Heymann S, Jacomy M (2009) Gephi: an open source software for exploring and manipulating networks. Paper presented at the Third international AAAI conference on weblogs and social media

Bollinger B (2015) Green technology adoption: an empirical study of the Southern California garment cleaning industry. Quant Mark Econ 13(4):319-358

Bosquet B, t. (2000) Environmental tax reform: does it work? A survey of the empirical evidence. Ecol Econ 34(1):19-32

Bressler MS, Bressler LA, Bressler ME (2011) A study of small business technology adoption and utilization. Academy of Entrepreneurship Journal 17(2)

Bukchin S, Kerret D (2019) Once you choose hope: early adoption of green technology. Environ Sci Pollut Res:1-10

Chandio AA, Magsi H, Ozturk I (2020) Examining the effects of climate change on rice production: case study of Pakistan. Environ SciPollut Res 27(8):7812-7822

Chen C (2015) The CiteSpace Manual 2014. In.

Chen C (2017) Science mapping: a systematic review of the literature. Journal of Data and Information Science 2(2):1-40

Chen L, Caro F, Corbett CJ, Ding X (2019) Estimating the environmental and economic impacts of widespread adoption of potential technology solutions to reduce water use and pollution: Application to China's textile industry. Environ Impact Assess Rev 79:106293
Chen J, Shi Q, Shen L, Huang Y, Wu Y (2019) What makes the difference in construction carbon emissions between China and USA? Sustain Cities Soc 44:604-613

Cherven, K. (2015). Mastering Gephi network visualization: Packt Publishing Ltd.

Cobo MJ, López-Herrera AG, Herrera-Viedma E, Herrera F (2011) Science mapping software tools: review, analysis, and cooperative study among tools. J Am Soc Inf Sci Technol 62(7):1382-1402

Coccia M (2020) Factors determining the diffusion of COVID-19 and suggested strategy to prevent future accelerated viral infectivity similar to COVID. Sci Total Environ 729:138474

Cohen M, Perakis G, Thraves C (2015a). Competition and externalities in green technology adoption. Available at SSRN 2607688.

Cohen MC, Lobel R, Perakis G (2015b) The impact of demand uncertainty on consumer subsidies for green technology adoption. Manag Sci 62(5): 1235-1258

Cohen MC, Lobel R, Perakis G (2016) The impact of demand uncertainty on consumer subsidies for green technology adoption. Manag Sci 62(5):1235-1258

Cunha-E-Sa MA, Reis AB (2007) The optimal timing of adoption of a green technology. Environ Resour Econ 36(1):35-55

Da Motta RS (2006) Analyzing the environmental performance of the Brazilian industrial sector. Ecol econ 57(2):269-281

Darko A, Chan AP (2016) Critical analysis of green building research trend in construction journals. Habitat International 57:53-63

Darko A, Chan AP, Huo X, Owusu-Manu D-G (2019) A scientometric analysis and visualization of global green building research. Build Environ 149:501-511

Darko A, Chan APC, Owusu-Manu D-G, Gou Z, Man JC-F (2020) Adoption of green building technologies in Ghana. In: Green Building in Developing Countries. Springer, pp 217-235

Ding Y (2011) Scientific collaboration and endorsement: network analysis of coauthorship and citation networks. Journal of Informetrics 5(1):187-203

Elcock D, Gasper J, Moses D, Emerson D, Arguero R (2000) Alternative future environmental regulatory approaches for petroleum refineries. Environ SciPolicy Sci 3(4):219-229

Elkington J, Rowlands IH (1999) Cannibals with forks: the triple bottom line of 21st century business. Altern J 25(4):42

Fernández-Navarro P, García-Pérez J, Ramis R, Boldo E, López-Abente G (2017) Industrial pollution and cancer in Spain: An important public health issue. Environ Res 159:555-563

Gallagher KS, Muehlegger E (2011) Giving green to get green? Incentives and consumer adoption of hybrid vehicle technology. $\mathrm{J}$ Environ Econ Manag 61(1):1-15

Glänzel W, Schubert A (2004) Analysing scientific networks through coauthorship. In: Handbook of quantitative science and technology research. Springer, pp 257-276

Gollin D, Morris M, Byerlee D (2005) Technology adoption in intensive post-green revolution systems. Am J Agric Econ 87(5):1310-1316

Gupta AK, Negi M, Nandy S, Kumar M, Singh V, Valente D, Pandey R (2020) Mapping socio-environmental vulnerability to climate change in different altitude zones in the Indian Himalayas. Ecol Indic 109:105787

He K, Zhang J, Wang X, Zeng Y, Zhang L (2018) A scientometric review of emerging trends and new developments in agricultural ecological compensation. Environ Sci Pollut Res 25(17):16522-16532

Hess DJ (1997) Science studies: An advanced introduction. NYU press

Hood W, Wilson C (2001) The literature of bibliometrics, scientometrics, and informetrics. Scientometrics 52(2):291-314

Hosseini MR, Maghrebi M, Akbarnezhad A, Martek I, Arashpour M (2018a) Analysis of citation networks in building information modeling research. J Constr Eng Manag 144(8):04018064

Hosseini MR, Martek I, Zavadskas EK, Aibinu AA, Arashpour M, Chileshe N (2018b) Critical evaluation of off-site construction research: a scientometric analysis. Autom Constr 87:235-247 
Hottenrott H, Rexhäuser S, Veugelers R (2016) Organisational change and the productivity effects of green technology adoption. Resour Energy Econ 43:172-194

Huang M-H, Chang Y-WJJOIS (2011) A study of interdisciplinarity in information science: using direct citation and co-authorship analysis. 37(4):369-378

Hussain J, Khan A, Zhou K (2020) The impact of natural resource depletion on energy use and $\mathrm{CO} 2$ emission in Belt \& Road Initiative countries: a cross-country analysis. Energy policy 199:117409

Hwang B-G, Zhao X, See YL, Zhong Y (2015) Addressing risks in green retrofit projects: the case of Singapore. Proj Manag J 46(4):76-89

Isik M (2004) Incentives for technology adoption under environmental policy uncertainty: implications for green payment programs. Environ Resour Econ 27(3):247-263

Khokhar D (2015) Gephi cookbook. Packt Publishing Ltd.

Kleinberg JM (1999) Authoritative sources in a hyperlinked environment. J ACM (JACM) 46(5):604-632

Knight LV, Steinbach TA (2008) Selecting an appropriate publication outlet: a comprehensive model of journal selection criteria for researchers in a broad range of academic disciplines. International Journal of Doctoral Studies 3

Koebel CT, McCoy AP, Sanderford AR, Franck CT, Keefe MJ (2015) Diffusion of green building technologies in new housing construction. Energy and Buildings 97:175-185

Konur O (2012) The evaluation of the global research on the education: a scientometric approach. Procedia Soc Behav Sci 47:1363-1367

Kumar R, Rao P, Areendran G (2020) Understanding Glacial Retreat in the Indian Himalaya: Historical Trends and Field Studies From a Large Glacier. Environmental Agricultural Informatics: Concepts, Methodologies, Tools, Applications, pp 1605-1622

Kurnia S, Choudrie J, Mahbubur RM, Alzougool B (2015) E-commerce technology adoption: A Malaysian grocery SME retail sector study. J Bus Res 68(9):1906-1918

Li C, Wu K, Wu J (2017) A bibliometric analysis of research on haze during 2000-2016. Environ Sci Pollut Res 24(32):24733-24742

Lin H, Zhu Y, Ahmad N, Han Q (2019) A scientometric analysis and visualization of global research on brownfields. Environ Sci Pollut Res:1-19

Mahmood H, Alkhateeb TTY, Furqan M (2020) Industrialization, urbanization and CO2 emissions in Saudi Arabia: Asymmetry analysis. Energy Rep 6:1553-1560

Marsilio M, Cappellaro G, Cuccurullo C (2011) The intellectual structure of research into PPPS: a bibliometric analysis. Public Manag Rev 13(6):763-782

Martins F, Felgueiras C, Smitková M (2018) Fossil fuel energy consumption in European countries. Energy Procedia 153:107-111

Meho LI, Rogers Y (2008) Citation counting, citation ranking, and hindex of human-computer interaction researchers: a comparison of Scopus and Web of Science. J Am Soc Inf Sci Technol 59(11): $1711-1726$

Murshed M (2020) Revisiting the deforestation-induced EKC hypothesis: the role of democracy in Bangladesh. GeoJournal, pp 1-22

Netusil N, Braden JB (2001) Transaction costs and sequential bargaining in transferable discharge permit markets. JEnviron Manage 61(3): 253-262

Olawumi TO, Chan DW (2018) A scientometric review of global research on sustainability and sustainable development. J Clean Prod $183: 231-250$

Olawumi TO, Chan DW, Wong JK (2017) Evolution in the intellectual structure of BIM research: a bibliometric analysis. J Civ Eng Manag 23(8):1060-1081

Ong P (2012) Environmental justice and green-technology adoption. Journal of Policy Analysis and Management 31(3):578-897

Pacala S, Socolow R (2004) Stabilization wedges: solving the climate problem for the next 50 years with current technologies. Science 305(5686):968-972
Pouchepparadjou A, Kumaravelu P, Achoth L (2005) An econometric analysis of green technology adoption in irrigated rice in Pondicherry union territory. Indian Journal of Agricultural Economics 60(902-2016-67450)

Pouris A, Pouris A (2010) Scientometrics of a pandemic: HIV/AIDS research in South Africa and the World. Scientometrics 86(2):541552

Prell C (2012) Social network analysis: history, theory and methodology. Sage

Ravindra K, Mor S (2019) Distribution and health risk assessment of arsenic and selected heavy metals in Groundwater of Chandigarh, India. Environ Pollut 250:820-830

Rennings K, Koschel H, Brockmann KL, Kühn I (1999) A regulatory framework for a policy of sustainability: lessons from the neo-liberal school. Ecol Econ 28(2):197-212

Santos R, Costa AA, Grilo A (2017) Bibliometric analysis and review of building information modelling literature published between 2005 and 2015. Autom Constr 80:118-136

Scherer RC (2005) Interdisciplinary research collaboration. Voice and Speech Review 4(1):329-336

Scholtens B (2005) Style and performance of Dutch socially responsible investment funds. J Invest 14(1):63-72

Schiederig T, Tietze F, Herstatt C (2012) Green innovation in technology and innovation management-an exploratory literature review. R\&D Manag 42(2):180-192

Sejati AW, Buchori I, Kurniawati S, Brana YC, Fariha TI (2020) Quantifying the impact of industrialization on blue carbon storage in the coastal area of Metropolitan Semarang. Indonesia. Appl Geogr 124:102319

Serenko A (2010) The development of an AI journal ranking based on the revealed preference approach. Journal of Informetrics 4(4):447-459

Shi X, Qian Y, Dong C (2017) Economic and environmental performance of fashion supply chain: The joint effect of power structure and sustainable investment. Sustainability 9(6):961

Shrivastava R, Mahajan P (2016) Artificial intelligence research in India: a scientometric analysis. Sci Technol Libr 35(2):136-151

Soares EV, Soares HM (2012) Bioremediation of industrial effluents containing heavy metals using brewing cells of Saccharomyces cerevisiae as a green technology: a review. Environ Sci Pollut Res 19(4):1066-1083

Song J, Zhang H, Dong W (2016) A review of emerging trends in global PPP research: analysis and visualization. Scientometrics 107(3): 1111-1147

Su H-N, Lee P-C (2010) Mapping knowledge structure by keyword cooccurrence: a first look at journal papers in Technology Foresight. Scientometrics 85(1):65-79

Tseng M-L, Islam MS, Karia N, Fauzi FA, Afrin S (2019) A literature review on green supply chain management: Trends and future challenges. Resour Conserv Recycl 141:145-162

Van Eck N, Waltman L (2009) Software survey: VOSviewer, a computer program for bibliometric mapping. Scientometrics 84(2):523-538

Van Eck N, Waltman L (2018) Manual for VOSviewer version 1.6. 8. CWTS Meaningful Metrics. Universiteit Leiden

Vergragt P, Akenji L, Dewick P (2014) Sustainable production, consumption, and livelihoods: global and regional research perspectives. J Clean Prod 63:1-12

Wang F, Li J, Tu WJPE (2017) Voluntary agreements, flexible regulation and CER: analysis of games in developing countries and transition economies. 174:377-384

Wang S, Chen M, Song M (2018) Energy constraints, green technological progress and business profit ratios: evidence from big data of Chinese enterprises. Int J Prod Res 56(8):2963-2974 
Wang X, Cho S-H, Scheller-Wolf A (2020) Green technology development and adoption: competition, regulation, and uncertainty-a global game approach. Manag Sci

Wang L, Yuan X, Liu C, Li Z, Chen F, Li S, Liu Y (2019) Soil C and N dynamics and hydrological processes in a maize-wheat rotation field subjected to different tillage and straw management practices. Agric Ecosyst Environ 285:106616

Watson RT, Boudreau M-C, Chen AJ, Sepúlveda HH (2011) Green projects: an information drives analysis of four cases. J Strateg Inf Syst 20(1):55-62

Weng X-H, Zhu Y-M., Song X-Y, Ahmad N (2019) Identification of key success factors for private science parks established from brownfield regeneration: a case study from China. 16(7), 1295. Retrieved from http://www.mdpi.com/1660-4601/16/7/1295

Wieringa, M., van Geenen, D., van Es, K., \& van Nuss, J. (2019). The fieldnotes plugin: making network visualization in Gephi accountable.

Xia D, Zhang M, Yu Q, Tu Y (2019) Developing a framework to identify barriers of green technology adoption for enterprises. Resour Conserv Recycl 143:99-110

Yao S, Song Y, Yu Y, Guo B (2020) A study of group decision-making for green technology adoption in micro and small enterprises. J Bus Ind Mark 36:86-96
Yoo S-C, Suh S-W (2020) Simulation of Environmental Changes Consdering Sea-level Rise Near a Mega-scale Coastal Dike (Saemangeum [SMG] Dike, Korea). J Coast Res 95(SI):309-314

Zailani S, Iranmanesh M, Nikbin D, Jumadi HB (2014) Determinants and environmental outcome of green technology innovation adoption in the transportation industry in Malaysia. Asian J Technol Innov 22(2):286-301

Zeng B, He Y (2019) Factors influencing Chinese tourist flow in Japan-a grounded theory approach. Asia PacJ Tour Res 24(1):56-69

Zhao X (2017) A scientometric review of global BIM research: analysis and visualization. Autom Constr 80:37-47

Zhao X, Zuo J, Wu G, Huang C (2019) A bibliometric review of green building research 2000-2016. Archit Sci Rev 62(1):74-88

Zhou Y, Xu G, Minshall T, Liu P (2015) How do public demonstration projects promote green-manufacturing technologies? A case study from China. Sustain Dev 23(4):217-231

Zuo J, Zhao Z-Y (2014) Green building research-current status and future agenda: a review. Renew Sust Energ Rev 30:271-281

Publisher's note Springer Nature remains neutral with regard to jurisdictional claims in published maps and institutional affiliations. 